\title{
Increased Metformin Clearance in Overweight and Obese Adolescents: A Pharmacokinetic Substudy of a Randomized Controlled Trial
}

\author{
Anne van Rongen ${ }^{1,2,5}$ (D) $\cdot$ Marloes P. van der Aa ${ }^{3} \cdot$ Maja Matic $^{4} \cdot$ Ron H. N. van Schaik ${ }^{4}$ \\ Vera H. M. Deneer ${ }^{1,6}$ - Marja M. van der Vorst $^{3}$ - Catherijne A. J. Knibbe ${ }^{1,2}$
}

Published online: 10 May 2018

(C) The Author(s) 2018

\begin{abstract}
Background In view of the increased use of metformin in obese adolescents, the aim of this study was to determine the pharmacokinetics of metformin in overweight and obese adolescents.

Methods In overweight and obese adolescents receiving metformin 500 or $1000 \mathrm{mg}$ twice daily for 37 weeks during a clinical trial, blood samples were collected over $8 \mathrm{~h}$ during an oral glucose tolerance test. Population pharmacokinetic modeling was performed using NONMEM.

Results Data for 22 overweight and obese adolescents with a mean total body weight (TBW) of $79.3 \mathrm{~kg}$ (range $54.7-104.9$ ), body mass index (BMI) of $29.1 \mathrm{~kg} / \mathrm{m}^{2}$ (range 22.9-39.3), and age of 15.9 years (range 11.1-17.5) were analysed. In the model, oral clearance $(\mathrm{CL} / F)$ of metformin $(1.17 \mathrm{l} / \mathrm{min}$ [relative standard error of $6 \%$ ]) increased
\end{abstract}

Electronic supplementary material The online version of this article (https://doi.org/10.1007/s40272-018-0293-1) contains supplementary material, which is available to authorized users.

Catherijne A. J. Knibbe

c.knibbe@antoniusziekenhuis.nl

1 Department of Clinical Pharmacy, St. Antonius Hospital, Nieuwegein, The Netherlands

2 Division of Pharmacology, Leiden Academic Centre for Drug Research, Leiden University, Leiden, The Netherlands

3 Department of Pediatrics, St. Antonius Hospital, Nieuwegein, The Netherlands

4 Department of Clinical Chemistry, Erasmus Medical Center, Rotterdam, The Netherlands

5 Present Address: Department of Clinical Pharmacy, Reinier de Graaf Hospital, Delft, The Netherlands

6 Present Address: Department of Clinical Pharmacy, University Medical Center Utrecht, Utrecht, The Netherlands significantly with TBW $(p<0.01)$. More specifically, CL/ $F$ increased with both developmental weight $\left(\mathrm{WT}_{\text {for age and length }}\right)$ and excess body weight $\left(\mathrm{WT}_{\text {excess }}\right)$, for which an excess weight covariate model was proposed. Conclusion The CL/F of metformin in obese adolescents $(1.17 \mathrm{l} / \mathrm{min})$ is larger than that in non-obese children $(0.55 \mathrm{l} / \mathrm{min})$ and similar to that in adults $(1.3 \mathrm{l} / \mathrm{min})$ as reported in the literature. This increase may potentially be explained by increased tubular secretion of metformin. These results appear to indicate that adult dosages of metformin could be considered in obese adolescents if pediatric dosages have been therapeutically ineffective. ClinicalTrials.gov NCT01487993.

\section{Key Points}

Oral clearance $(\mathrm{CL} / F)$ of metformin increases significantly with total body weight (TBW) in overweight and obese adolescents.

The $\mathrm{CL} / F$ in obese adolescents is higher than in nonobese children and comparable to adult values reported in the literature.

These results indicate that adult dosages of metformin (i.e., $3 \mathrm{~g}$ per day) could be considered in obese adolescents if pediatric dosages have been therapeutically ineffective. 


\section{Introduction}

Worldwide prevalence rates of obesity are increasing, and this is not only restricted to adults. In the USA, $34.5 \%$ of adolescents (aged 12-19 years) were overweight (body mass index [BMI] for age $\geq 85$ th percentile) and $20.5 \%$ were obese (BMI for age $\geq 95$ th percentile) in 2011-2012 [1]. In Western Europe, prevalence rates of obesity (based on International Obesity Task Force cut-offs) ranged from 3.8 to $13.5 \%$, whereas percentages in North Africa and the Middle East ranged from 4.2 to $23.3 \%$ in boys and girls (aged $<20$ years) in 2013 [2]. Obesity is the most common cause of insulin resistance in children and adolescents [3] and a known risk factor for type 2 diabetes mellitus (T2DM) [4]. Metformin is a registered drug for the treatment of T2DM in pediatric patients aged $>10$ years. Recently, a large increase in prescriptions of metformin or other oral antidiabetic drugs was observed in children $[5,6]$, suggesting that metformin is prescribed not only in children with T2DM but also in obese children with type 1 diabetes mellitus in addition to insulin and for obesity with or without insulin resistance [5]. To date, except for one abstract of a study in obese adolescents with T2DM [8], the pharmacokinetics of metformin have only been studied in non-obese children who received metformin for earlynormal onset of puberty [7]. While tubular secretion is the primary route of elimination, conducted by organic cation transporters (OCT2) (basolateral membrane of the renal tubule cells; uptake of metformin in the renal tubule cells) and human multidrug and toxin extrusion transporters (i.e., MATE1 and MATE2K) (apical membrane of the renal tubules; transports metformin out of the tubule cells) $[9,10]$, the influence of obesity on the expression or activity of these renal transporters is largely unknown. The OCT1 transporter is expressed on the apical membrane of the renal tubule and may play a role in the reabsorption of metformin [9]. The aim of this study was to determine the pharmacokinetics of metformin in overweight and obese adolescents enrolled in a multicentre randomized doubleblind controlled trial investigating the short- and long-term efficacy and safety outcomes of metformin [11].

\section{Methods}

\subsection{Patients}

The clinical trial protocol of the multicentre randomized double-blind controlled study on short- and long-term efficacy and safety outcomes of metformin are described elsewhere [11] and repeated briefly here as relevant to this pharmacokinetic sub-study. Obese adolescents were recruited at the pediatric outpatient clinic of the St. Antonius Hospital Nieuwegein and Jeroen Bosch Hospital in 'sHertogenbosch, the Netherlands. Patients were eligible for inclusion if they were aged 10-16 years, obese (defined as BMI-standard deviation score [SDS] $>2.3$ at pre-study screening), insulin resistant (defined as homeostatic model assessment-insulin resistance [HOMA-IR] $\geq 3.4$ at prestudy screening), and of Caucasian descent. Patients were excluded if they had T2DM, polycystic ovary syndrome, or endocrine disorders for which treatment with corticosteroids was indicated. Also excluded were patients with a height $\leq 1.3$ standard deviation (SD) of target height, (history of) alcohol abuse, impaired renal function (glomerular filtration rate $[\mathrm{GFR}]<80 \mathrm{ml} / \mathrm{min}$ ), or impaired hepatic function (alanine aminotransferase [ALT] $>150 \%$ of normal value for age) and patients who used anti-hyperglycemic drugs or who were pregnant. Before participation, parents and patients provided written informed consent and assent, respectively. The study was approved by the local human research and ethics committee of the St. Antonius Hospital (VCMO, NL34611.100.11) and was conducted in accordance with the principles of the Declaration of Helsinki and the Medical Research Involving Human Subjects Act (WMO) of the Netherlands.

\subsection{Study Design}

In this multicentre randomized double-blind trial (NCT01487993 and EudraCT 2010-023980-17), 23 overweight and obese adolescents of the metformin arm participated in the pharmacokinetic study, which was performed during an oral glucose tolerance test (OGTT). At the time of the pharmacokinetic sub-study, patients had received metformin 500 or $1000 \mathrm{mg}$ (Centrapharm, Etten leur, the Netherlands) twice daily for 37 weeks [11]. Patients were asked to fast overnight and postpone their morning metformin dose until arrival at the outpatient clinic. After insertion of a venous cannula, patients received a solution of glucose $1.75 \mathrm{~g} / \mathrm{kg}$ body weight (maximum $75 \mathrm{~g}$ ) dissolved in 200 or $300 \mathrm{ml}$ of water. Directly after ingestion of the glucose solution, the metformin tablet was ingested (500 or $1000 \mathrm{mg}$ ). Blood samples were collected before the metformin dose (trough concentration) and at $60,120,240,360$, and $480 \mathrm{~min}$, centrifuged at 4000 RPM ( $g$ ) for 5 min and stored at $20{ }^{\circ} \mathrm{C}$ until analysis. In addition, blood samples for creatinine, ALT, and DNA to determine the genetic variation in the OCT1 and MATE1 transporters were collected.

\subsection{Drug Assay}

Serum metformin concentrations were quantified using high-performance liquid chromatography (HPLC). For 
sample preparation, $50 \mu \mathrm{l}$ of internal standard (phenformin $500 \mathrm{mg} / \mathrm{l}$ in methanol) and $250 \mu \mathrm{l}$ of acetonitrile were added to $100 \mu \mathrm{l}$ of the sample. After vortex mixing, this mixed sample was centrifuged at $4000 \mathrm{~g}$ for $10 \mathrm{~min}$. Ten microliter of the supernatant was injected into the HPLC column (Zorbax SB-CN $5 \mu \mathrm{m} 4.6 \times 150 \mathrm{~mm}$ [Agilent]), protected by a precolumn (H3-10C5 [Hichrom]), which was kept at $30{ }^{\circ} \mathrm{C}$ and detected by a photodiode array detector $(234 \mathrm{~nm})$. Isocratic elution was performed with a mobile phase consisting of sodium sulphate ( $\mathrm{pH}$ of 2.3 ) and acetonitrile in a 770:230 ratio at a flow rate of $1.2 \mathrm{ml} / \mathrm{min}$. The elution times for metformin and the internal standard were 2.1 and $3.0 \mathrm{~min}$, respectively. The assay was linear over $0.2-5.0$, and $0.2 \mathrm{mg} / \mathrm{l}$ was the limit of quantification (LOQ). Intra- and inter-assay coefficients of variation were within $0.8-3.6$ and $4-8.5 \%$, respectively. The concentrations of the quality controls were $0.5,2.5$, and $4.5 \mathrm{mg} / \mathrm{l}$ (low, middle and high, concentration, respectively).

\subsection{DNA Analysis}

DNA was isolated from whole blood on the MagNA Pure LC 2.0 instrument (Roche ${ }^{\circledR}$ ). Ready-made TaqMan assays were used for determination of OCT1 (rs72552763, rs12208357, rs34130495, rs34059508, and rs622342) and MATE1 (rs2289669, rs10735) polymorphisms on the ABI PRISM $^{\circledR} 7500$ Real-Time polymerase chain reaction system (Applied Biosystems ${ }^{\circledR}$, Bleiswijk, the Netherlands). Violation of Hardy-Weinberg (HW) equilibrium was tested with the Chi squared test. In addition, observed minor allele frequencies were compared with the frequencies found in the single nucleotide polymorphism (SNP) database of the National Center for Biotechnology Information. The OCT1 haplotype, defined by the presence of one or more of the genetic variants rs72552763, rs12208357, rs34130495, and rs34059508 was estimated with the haplo.stats package ( $\mathrm{R}$, version 3.1.1), which uses the expectation-maximization logarithm and a posterior probability $>0.98$.

\subsection{Statistical Analysis}

The area under the curve concentrations from 0 to $8 \mathrm{~h}$ after dose $\left(\mathrm{AUC}_{0-8 \mathrm{~h}}\right)$ and $\mathrm{AUC}$ until infinity $\left(\mathrm{AUC}_{\mathrm{inf}}\right)$ for metformin were calculated for each patient separately using the linear trapezoidal rule in $\mathrm{R}$ software (version 3.0.1) [12]. Seven patients had metformin concentrations measured until $7 \mathrm{~h}$ post-dose and for these patients the $\mathrm{AUC}_{0-8 \mathrm{~h}}$ was calculated based on extrapolation until $8 \mathrm{~h}$. The calculated $\mathrm{AUC}_{0-8 \mathrm{~h}}$ and $\mathrm{AUC}_{\mathrm{inf}}$ were standardized for the administered dose (1000 $\mathrm{mg}$ ), as patients received metformin 500 or $1000 \mathrm{mg}$. The Pearson correlation test was applied to test the correlation between total body weight (TBW) and

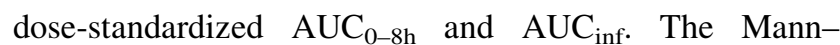
Whitney test or Kruskal-Wallis test was applied to test statistical differences in dose-standardized $\mathrm{AUC}_{0-8 \mathrm{~h}}$ or dose-standardized $\mathrm{AUC}_{\mathrm{inf}}$ and different genotype groups of the OCT1 and MATE1 transporter. Statistical analyses were performed using IBM SPSS software, version 22.

\subsection{Population Pharmacokinetic Analysis and Internal Model Validation}

Metformin data were analyzed using non-linear mixed effects modeling with NONMEM (version 7.2; ICON Development Solutions, Hanover, MD, USA) [13]. Pirana (2.9.1) [14], R (3.0.1) [12], Xpose (4.5.0) [14], and Psn (3.6.2) [14] were used to evaluate and visualize the data. Of the 129 metformin samples, seven trough samples $(5.4 \%)$ and one post-dose sample (at $8 \mathrm{~h} ; 0.8 \%$ ) were below the LOQ. One trough sample below the LOQ of $0.2 \mathrm{mg} / \mathrm{l}$ (i.e., $0.12 \mathrm{mg} / \mathrm{l}$ ) was kept in the dataset, whereas no metformin could be detected for the other samples below LOQ, so these samples were subsequently removed from the analysis $[15,16]$. The first-order conditional estimation method with interaction was used for model development. Discrimination between different models was guided by the likelihood ratio test, by comparison of the objective function value (OFV, i.e., $-2 \log$ likelihood [ $-2 \mathrm{LL}]$ ) between nested models. A $p$ value of $<0.05$, representing a decrease of 3.84 in OFV for one degree of freedom, was considered statistically significant. In addition, goodnessof-fit plots for metformin (observed vs. individual predicted concentrations, observed vs. population predicted concentrations, conditional weighted residuals vs. time after dose, and conditional weighted residuals vs. population predicted concentrations plots) were used for diagnostic purposes. Furthermore, precision of parameter estimates, the correlation matrix, and visual improvement in the individual plots were used to evaluate the model. Pharmacokinetic models incorporating either one or two compartments with first-order, zero-order, or combined first- and zero order oral absorption were tested. Furthermore, the addition of one or more transit compartments [17] or an oral absorption lag time was evaluated. Interindividual variability (IIV) was assumed to follow a log-normal distribution. Residual variability was tested using proportional, additive, or combined proportional and additive error models for metformin. For internal model evaluation, we used a bootstrap resampling method using 1000 replicates and prediction-corrected visual predictive check (pcVPC) [18] using 1000 simulated datasets of individuals from the original dataset. 


\subsection{Covariate Model}

Tested covariates were TBW, BMI, BMI-SDS, lean body weight (LBW) according to the equations of Janmahasatian et al. [19], Foster et al. [20] and Peters et al. [21] and waist-hip ratio, age, sex, creatinine, and estimated GFR (eGFR) according to the bedside Schwartz formula [22]. In addition, the influence of genetic polymorphisms of the OCT1 and MATE1 transporter were tested. Covariates were plotted independently against the eta $(\eta)$ estimates of the pharmacokinetic parameters to visualize potential relations. Continuous covariates were tested using linear and power equations (Eqs. 1, 2):

$P_{i}=P_{p} \times\left(1+V \times\left(\mathrm{COV}-\mathrm{COV}_{\text {median }}\right)\right)$

$P_{i}=P_{p} \times\left(\mathrm{COV} / \mathrm{COV}_{\text {median }}\right)^{W}$,

where $P_{i}$ and $P_{p}$ represent individual and population parameter estimates, respectively, COV represents the covariate, $\mathrm{COV}_{\text {median }}$ represents the median value of the covariate for the population, $V$ represents a correlation factor between the population pharmacokinetic parameter and the change in covariate value for a linear function, and $W$ represents the exponent for a power function. The categorical covariates sex and genetic polymorphisms of the OCTI and MATE1 transporter were examined by calculating a separate parameter for each category of the covariate. Based on OCT1 (rs622342) and MATE1 (rs2289669 and rs10735) genotype, subjects were categorized into two groups: variants (homozygous and heterozygous variants) or wild types. For $O C T 1$ haplotype, subjects were categorized as normal transporter activity or decreased and absent transporter activity. In addition, different combinations of the genotypes were tested, for example between the OCT1 (rs622342) and MATE1 (rs2289669) transporter [23].

Potential covariates were entered into the model one at a time and statistically tested using the likelihood ratio test. In addition, if applicable, reduction in IIV (omega $[\omega]$ ) of the parameter was evaluated upon inclusion of the covariate on the parameter. Further, trends in the random effects of the parameter versus the covariate involved were observed. Finally, after forward inclusion $(p<0.05)$, a backward exclusion procedure was applied to justify the inclusion of a covariate $(p<0.01)$. The choice of the final covariate model was further evaluated as discussed in Sect. 2.6.

\subsection{Excess Weight Covariate Model}

To further analyze the influence of (over)weight on the pharmacokinetics of metformin, an excess weight model was tested for the parameters for which TBW proved a covariate given the criteria described in Sect. 2.6. Using this covariate model, the TBW of each individual patient was considered to be composed of two parts: developmental weight $\left(\mathrm{WT}_{\text {for age and length }}\right)$ and excess body weight $\left(\mathrm{WT}_{\text {excess }}\right)$ [24], whereas separate functions for each of these weights were used.

For each individual patient in the study, $\mathrm{WT}_{\text {for age and length }}$ was derived from the Dutch TNO growth calculator [25] on the basis of the length and age of the patient at a BMI-SDS score of 0 (no overweight) [25]. $\mathrm{WT}_{\text {excess }}$ and relative $\mathrm{WT}_{\text {excess }}\left(\% \mathrm{WT}_{\text {excess }}\right)$ were calculated using Eqs. (3) and (4), respectively, for each individual patient:

$\mathrm{WT}_{\text {excess }}=\mathrm{TBW}-\mathrm{WT}_{\text {for age and length }}$

$\% \mathrm{WT}_{\text {excess }}=\left(\mathrm{WT}_{\text {excess }} / \mathrm{WT}_{\text {for age and length }}\right) \times 100 \%$.

First, $\mathrm{WT}_{\text {for age and length }}, \mathrm{WT}_{\text {excess }}$, and $\% \mathrm{WT}_{\text {excess }}$ were all plotted independently against the eta estimate of the pharmacokinetic parameter of interest to visualize the relation.

The separate impact of $\mathrm{WT}_{\text {for age and length }}$ and $\mathrm{WT}_{\text {excess }}$ on clearance in adolescents was evaluated using Eqs. (5) and (6):

$$
\begin{aligned}
\mathrm{CL}_{\text {non-obese adolescent }}= & \mathrm{CL}_{70 \mathrm{~kg} \text { adult }} \\
& \times\left(\mathrm{WT}_{\text {for age and length }} / 70\right)^{0.75} \\
\mathrm{CL}_{(\text {obese }) \text { adolescent }}= & \mathrm{CL}_{\text {non-obese adolescent }}+\left(\mathrm{Z} \times \mathrm{WT}_{\text {excess }}\right)
\end{aligned}
$$

in which $\mathrm{CL}_{\text {non-obese adolescent }}$ represents the clearance estimate of adolescents without overweight, $\mathrm{CL}_{70 \mathrm{~kg}}$ adult represents the population clearance of an adult weighing $70 \mathrm{~kg}, \mathrm{WT}_{\text {for age and length }}$ represents developmental weight, 0.75 is the scaling factor previously proposed by the US FDA for scaling clearance from adults to adolescents [26], $\mathrm{CL}_{\text {(obese) adolescent }}$ is the individual clearance estimates of (obese) adolescents, and $Z$ is the linear influence of $\mathrm{WT}_{\text {excess }}$ in this function.

\section{Results}

\subsection{Patients and Data}

In total, 23 patients participated in the pharmacokinetic study. One patient was excluded from the analysis because of interference of comedication at the metformin peak of the chromatogram of the drug assay. In total, 22 patients were included in the analysis, from which a total of 122 metformin serum samples were available. Three patients were receiving oral metformin $500 \mathrm{mg}$ and 19 patients were receiving oral metformin $1000 \mathrm{mg}$. Table 1 presents a 
summary of all patient characteristics, and Table 1 in the Electronic Supplementary Material (ESM) presents the allele frequencies of the OCT1 and MATE1 polymorphisms, showing that all polymorphisms were in line with the HW equilibrium.

\subsection{Observed Metformin Concentrations}

The absorption of metformin in overweight and obese adolescents proved variable, with a median time to maximum plasma concentration $\left(T_{\max }\right)$ of $120 \mathrm{~min}$ (range 60-240) and a median maximum plasma drug concentration $\left(C_{\max }\right)$ of $1.80 \mathrm{mg} / \mathrm{l}$ (range $0.79-3.45$ ). In nine patients, fast absorption was observed, with a $T_{\max }$ of $60 \mathrm{~min}$. The median dose-standardized (1000 mg) $\mathrm{AUC}_{0-8}$ and $\mathrm{AUC}_{\text {inf }}$ of metformin in 22 overweight and obese adolescents was $603.5 \mathrm{mg} \times \mathrm{min} / \mathrm{l}$ (range 286.7-1118.2) and $802.7 \mathrm{mg} \times \mathrm{min} / 1$ (range 322.8-2568.8), respectively. Dose-standardized $\mathrm{AUC}_{0-8}$ and $\mathrm{AUC}_{\text {inf }}$ of metformin significantly decreased with TBW $(r=-0.46, p=0.032$, and $r=-0.47, p=0.027$, respectively). Genetic variation in the OCT1 and MATE1 transporter did not have a significant influence on the dose-standardized $\mathrm{AUC}_{0-8}$ and AUC $_{\text {inf }}$ of metformin $(p>0.05)$.

\subsection{Population Pharmacokinetic Model and Internal Model Validation}

A one-compartment model with first-order absorption of metformin best described the data. The pharmacokinetic model was parameterized in terms of oral absorption rate constant $(\mathrm{Ka})$, oral volume of distribution $(V / F)$, and oral clearance $(\mathrm{CL} / F)$ from the central compartment. Residual variability was best described by a proportional error model. Table 2 shows the parameter estimates of the base model without covariates.

In the covariate analysis, a significant influence of TBW and LBW according to the equation of Peters et al. [21] were found for $\mathrm{CL} / F$ of metformin in a linear manner $(p<0.01,-6.6 \Delta \mathrm{OFV}$, and $-7.6 \Delta \mathrm{OFV})$, upon which the covariate model with TBW was chosen as final model. Figure 1 shows the Empirical Bayes estimates (EBEs) for $\mathrm{CL} / F$ of metformin together with the covariate function of the final model. Renal function determined by eGFR was not a significant covariate for $\mathrm{CL} / F$, which may also be because no children with eGFR $<80 \mathrm{ml} / \mathrm{min}$ could be included in this study. No other covariates were identified as a significant covariate for any of the pharmacokinetic parameters $(p>0.05)$.

Genetic polymorphisms of the OCT1 and MATE1 transporter or any combination of genotypes were not significantly influential on any of the pharmacokinetic parameters $(p>0.05)$. OCT1 haplotype (the four SNPs rs72552763, rs12208357, rs34130495, rs34059508) showed a trend with $\mathrm{Ka}$, but problems occurred with the minimization and the $\mathrm{Ka}$ could not be estimated with adequate precision.

Table 2 summarizes the parameters of the final model, and Fig. 1 in the ESM shows the goodness-of-fit plots of metformin. The bootstrap analysis confirms the results of the model, with parameter estimates and eta estimates within 8.5 and $14 \%$, respectively, compared with those obtained within the original dataset (Table 2). In addition, prediction-corrected VPC (pcVPC) for metformin indicated good predictive performance with good agreement between observed data and model-simulated confidence
Table 1 Demographic parameters of 22 overweight and obese adolescents

\begin{tabular}{ll}
\hline Characteristic & Overweight and obese adolescents $(n=22)$ \\
\hline Female/male $(n)$ & $16 / 6$ \\
Overweight/obese & $5 / 17$ \\
Age (years) & $14.5 \pm 1.8(11.1-17.5)$ \\
Body weight $(\mathrm{kg})$ & $79.3 \pm 13.9(54.7-104.9)$ \\
BMI $\left(\mathrm{kg} / \mathrm{m}^{2}\right)$ & $29.1 \pm 4.4(22.9-39.3)$ \\
BMI-SDS & $2.8 \pm 0.6(1.7-4.0)$ \\
Waist-hip ratio & $1.0 \pm 0.06(0.9-1.1)$ \\
LBW $(\mathrm{kg})$ eq. Janmahasatian et al. [19] & $49.0 \pm 8.7(35.3-71.1)$ \\
LBW $(\mathrm{kg})$ eq. Foster et al. [20] & $48.6 \pm 8.6(35.4-72.8)$ \\
LBW $(\mathrm{kg})$ eq. Peters et al. [21] & $55.5 \pm 7.5(41.7-71.0)$ \\
Creatinine $(\mu \mathrm{mol} / \mathrm{l})$ & $54.5 \pm 7.0(44-69)$ \\
eGFR $\left(\mathrm{ml} / \mathrm{min} / 1.73 \mathrm{~m}^{2}\right)$ [22] & $111.8 \pm 12.2(94.1-135.8)$ \\
\hline
\end{tabular}

Values are expressed as mean \pm standard deviation (range) unless specified otherwise

$B M I$ body mass index, $B M I-S D S$ body mass index standard deviation score, $e G F R$ estimated glomerular filtration rate, eq. equation, $L B W$ lean body weight 
Table 2 Population pharmacokinetic parameters of the base model, excess weight covariate model, and final covariate model for metformin in 22 overweight and obese adolescents and results from a bootstrap analysis of the final model (995/1000 resamples successful)

\begin{tabular}{|c|c|c|c|c|}
\hline Parameter & $\begin{array}{l}\text { Base model } \\
\text { (RSE\%) }\end{array}$ & $\begin{array}{l}\text { Excess weight model } \\
\text { (RSE\%) }\end{array}$ & $\begin{array}{l}\text { Final covariate model } \\
\text { (RSE\%) }\end{array}$ & Bootstrap $(95 \% \mathrm{CI})$ \\
\hline CL/F (1/min) & $1.21(7)$ & - & - & - \\
\hline \multicolumn{5}{|c|}{$\begin{array}{l}\mathrm{CL} / F=\mathrm{CL} / F_{70 \mathrm{~kg}} \times\left(\mathrm{WT}_{\text {for age and length }} /\right. \\
70)^{0.75}+\left(Z \times \mathrm{WT}_{\text {excess }}\right)\end{array}$} \\
\hline $\mathrm{CL} / F_{70 \mathrm{~kg}}$ & - & $1.16(16)$ & - & - \\
\hline$Z$ & - & $0.011(52)$ & - & - \\
\hline \multicolumn{5}{|c|}{$\mathrm{CL} / F=\mathrm{CL} / F_{75.8 \mathrm{~kg}} \times(1+\mathrm{V} \times(\mathrm{TBW}-75.8)$} \\
\hline $\mathrm{CL} / F_{75.8 \mathrm{~kg}}$ & - & - & $1.17(6)$ & $1.18(1.04-1.36)$ \\
\hline$V$ & - & - & $0.0138(44)$ & $\begin{array}{l}0.0126 \\
\quad(0.0035-0.0291)\end{array}$ \\
\hline$V / F(\mathrm{~L})$ & $488(10)$ & $486(10)$ & $485(10)$ & $481.8(396.8-607.8)$ \\
\hline $\mathrm{Ka}\left(\min ^{-1}\right)$ & $0.0253(25)$ & $0.025(25)$ & $0.0248(25)$ & $\begin{array}{l}0.0252 \\
\quad(0.0159-0.0563)\end{array}$ \\
\hline \multicolumn{5}{|c|}{ Interindividual variability (\%) } \\
\hline $\mathrm{CL} / F$ & $31.6(29)[4]$ & $26.5(32)[6]$ & 26.8 (31) [6] & $24.8(5.5-40.3)$ \\
\hline$V / F$ & 37 (17) [14] & 36.5 (17) [14] & $36.2(16)[14]$ & $33.8(18.2-46.4)$ \\
\hline $\mathrm{Ka}$ & $74.2(21)[31]$ & $71.4(22)[32]$ & $70.3(22)[32]$ & $65.4(26.7-132.9)$ \\
\hline \multicolumn{5}{|c|}{ Residual variability (\%) } \\
\hline Proportional error & $21.7(25)[19]$ & $21.8(25)[18]$ & $21.8(25)[18]$ & $22.0(16.1-27.5)$ \\
\hline OFV & -134.4 & -140.8 & -141.0 & $\begin{array}{l}-150.7(-204.4 \text { to } \\
-108.0)\end{array}$ \\
\hline
\end{tabular}

$C I$ confidence interval, $C L / F$ oral clearance, $K a$ absorption rate constant, $O F V$ objective function value, $R S E$ relative standard error, $T B W$ total body weight, $V / F$ oral volume of distribution, $W T_{\text {excess }}$ excess body weight, $W T_{\text {for age and length }}$ developmental weight

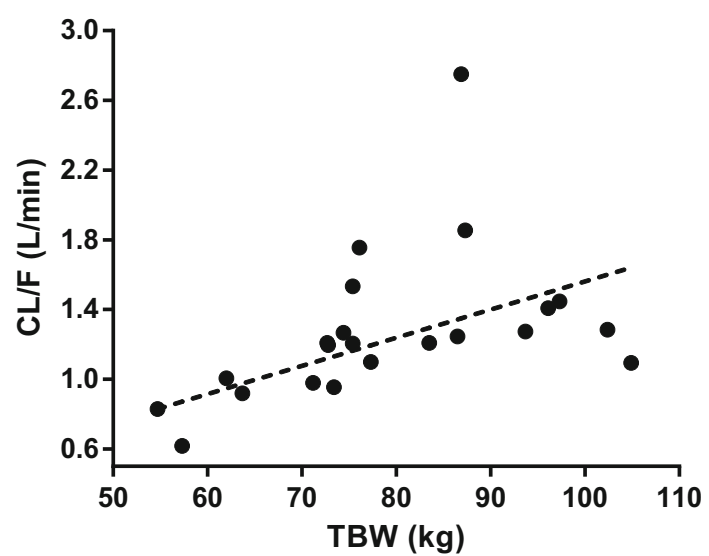

Fig. 1 Empirical Bayes estimates for oral clearance $(\mathrm{CL} / F)$ of metformin versus total body weight (TBW) with the covariate relation between CL/F and TBW for the final covariate model

intervals for the median, 2.5th and 97.5th percentiles (Fig. 2).

To further analyze the influence of (over)weight on the $\mathrm{CL} / F$ of metformin, Fig. 3 shows clearance versus developmental weight $\left(\mathrm{WT}_{\text {for age and length }}\right)$ and versus excess

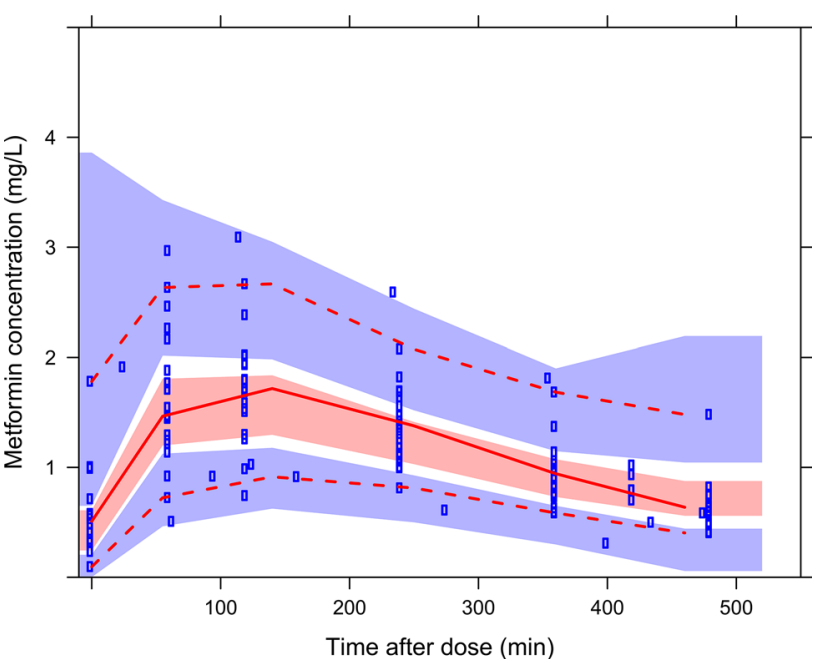

Fig. 2 Prediction-corrected visual predictive checks of the final model for metformin. Observed concentrations are shown as blue circles with solid, lower and upper dashed red lines showing the median, 2.5th and 97.5th percentiles of the observed data, respectively. The shaded areas represent $95 \%$ confidence intervals for the median, 2.5th and 97.5th percentiles of simulated concentrations $(n=1000)$, based on the original dataset 
Fig. 3 Empirical Bayes estimates for a oral clearance $(\mathrm{CL} / F)$ of metformin versus developmental weight $\left(\mathrm{WT}_{\text {for age and length }}\right)$ and b excess body weight $\left(\mathrm{WT}_{\text {excess }}\right)$ of the base model
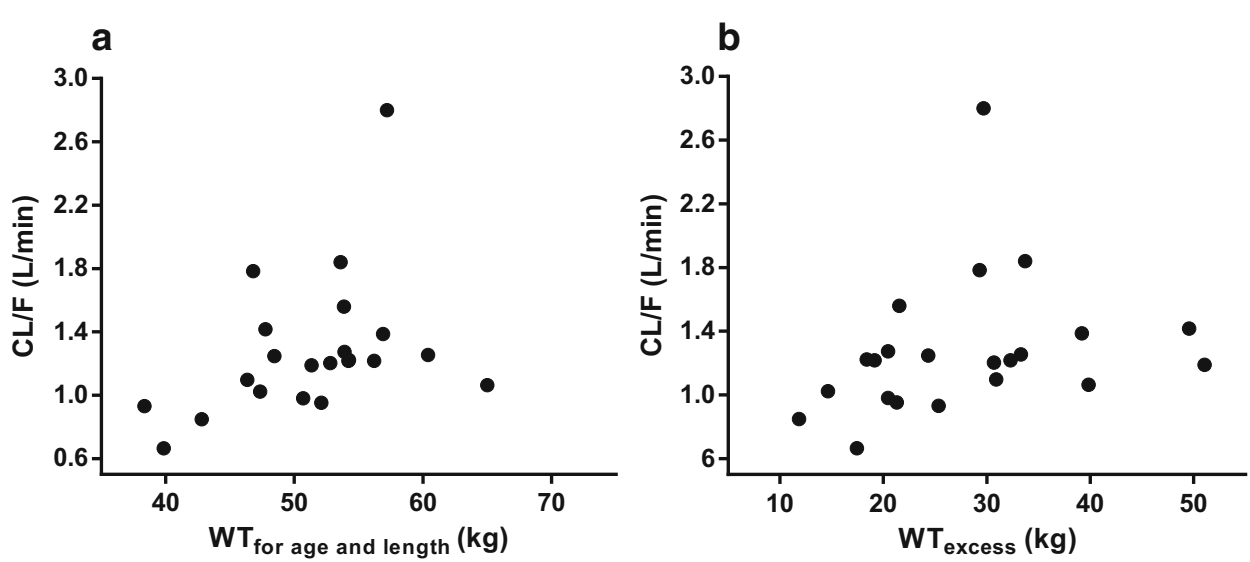

body weight ( $\mathrm{WT}_{\text {excess}}$ ) (Fig. 3a, b), with positive trends for both weight measures $(\triangle \mathrm{OFV}-5.5$ and -4.2 , respectively; $p<0.05)$. No significant trend was observed for $\% \mathrm{WT}_{\text {excess }}(p>0.05)$. To capture the contribution of these different weight measures in obese adolescents, an excess weight covariate model (Eqs. 5, 6) was applied, in which $\mathrm{WT}_{\text {for age and length }}$ scaled on the basis of $70 \mathrm{~kg}$ to the power of 0.75 (Eq. 5) [26], whereas a separate function was estimated for $\mathrm{WT}_{\text {excess }}$ (Eq. 6). Figure 4 and Table 2 show the results of this approach in which the final covariate model for clearance was replaced by the excess weight covariate model. They illustrate that $\mathrm{WT}_{\text {for age and length }}$ scales allometrically to the power of

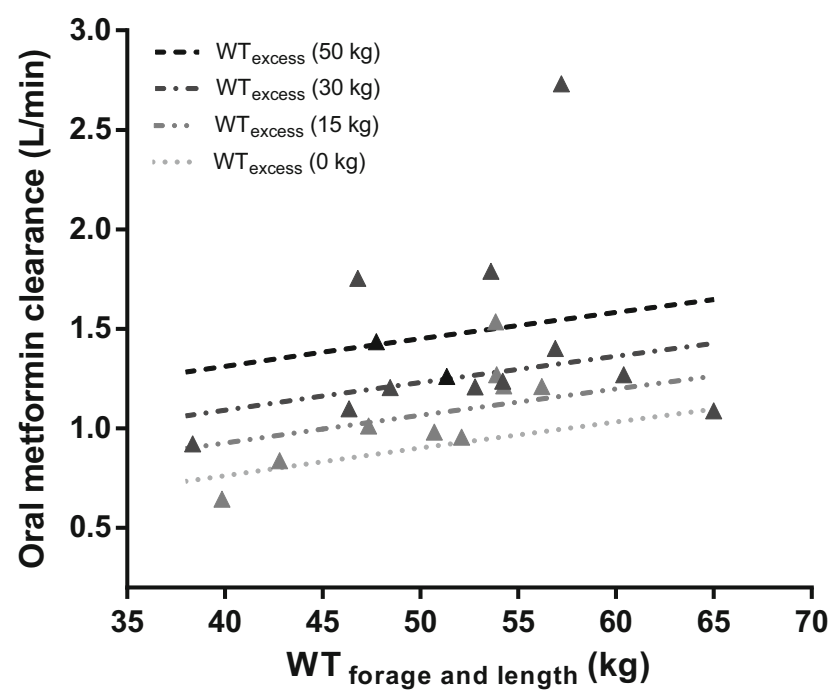

Fig. 4 Oral metformin clearance (population prediction [line] and empirical Bayes estimates [triangles]) from 22 overweight and obese adolescents versus $\mathrm{WT}_{\text {for age and length }}$ for different $\mathrm{WT}_{\text {excess }}$ levels (i.e., 15, 30, and $50 \mathrm{~kg}$, dark grey/black lines). Population values for oral clearance are composed of the clearance of non-obese adolescents $\left(\mathrm{WT}_{\text {excess } 0 \mathrm{~kg}}\right.$, light grey dotted line) plus an increase related to $\mathrm{WT}_{\text {excess }}$ according to Eqs. (5) and (6). Observed individual values of obese adolescents are represented by triangles with grey/black scales varying according to the degree in $\mathrm{WT}_{\text {excess. }} W T_{\text {excess }}$ excess body weight, $W T_{\text {for age and length }}$ developmental weight
0.75 , with an additional increase in clearance depending on $\mathrm{WT}_{\text {excess }}$ (varying between 0 and $50 \mathrm{~kg}$ ). Both the excess weight covariate model (Fig. 4 and Table 2) and the final covariate model (Table 2) performed similarly in describing the data in terms of OFV $(-140.8$ vs. -141.0 ; $p>0.05)$ and goodness-of-fit plots.

\section{Discussion}

This study aimed to determine the pharmacokinetics of metformin in overweight and obese adolescents in view of the increasing use of metformin for obesity in children, in whom adult dosages are often used. This study shows that the AUC decreases and the CL/F of metformin increases significantly with TBW in obese adolescents (Fig. 1). The increase in $\mathrm{CL} / F$ can be explained by both $\mathrm{WT}_{\text {for age and length }}$ and $\mathrm{WT}_{\text {excess }}($ Fig. 3a, b), for which an excess weight covariate model was proposed in which

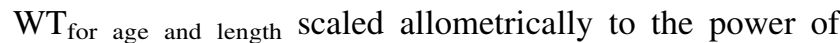
0.75 and a separate function for $\mathrm{WT}_{\text {excess }}$ was estimated. This excess covariate weight model was applied because the interrelation between growth, age, and obesity in obese children and adolescents complicates a systematic covariate analysis [24, 27].

When the current pharmacokinetic parameters of metformin in overweight and obese adolescents are compared with literature values of non-obese children and (obese) adults (Table 3), the dose-standardized AUC value we report here in overweight and obese adolescents proved about two times lower than in non-obese children [7]. However, this AUC is around the same as in obese T2DM adolescents [8] and healthy adult subjects [8], and similar to or higher than in obese adults [28] (Table 3). These results indicate that obese adolescents have a higher clearance than their non-obese counterparts [7] (Table 3), whereas, within the obese adolescent population, $\mathrm{CL} / F$ increased even further in more severely obese individuals 
Table 3 Pharmacokinetic parameters of oral metformin in overweight and obese adolescents from this study compared with literature values from different patient populations

\begin{tabular}{|c|c|c|c|c|c|c|c|}
\hline Population & $\begin{array}{l}\text { Study } \\
\text { design }\end{array}$ & TBW (kg) & Age (years) & $\begin{array}{l}\mathrm{AUC}^{\mathrm{a}} \\
(\mathrm{mg} \times \mathrm{min} / \mathrm{l})\end{array}$ & $\mathrm{CL} / F(1 / \mathrm{min})$ & $V / F(1)$ & $\mathrm{Ka}\left(\min ^{-1}\right)$ \\
\hline $\begin{array}{l}\text { Obese adolescents from this } \\
\text { study }\end{array}$ & Fasted & $79.3 \pm 13.9$ & $14.5 \pm 1.8$ & $\begin{array}{l}\mathrm{AUC}_{0-\text { inf }} \\
\quad 460.5 \pm 223 \\
\mathrm{AUC}_{0-8} \\
\quad 316.5 \pm 101.6\end{array}$ & $1.17^{\mathrm{b}}$ & $485^{\mathrm{b}}$ & $0.0248^{\mathrm{b}}$ \\
\hline Non-obese children [7] & Dinner & $33.3 \pm 2.7$ & $9.5 \pm 0.1$ & $\begin{array}{l}\mathrm{AUC}_{0-12} \\
\quad 816.2 \pm 57.8\end{array}$ & $0.55 \pm 0.55^{\mathrm{c}}$ & $185 \pm 11.7^{\mathrm{d}}$ & $0.0175 \pm 0.0045$ \\
\hline $\begin{array}{l}\text { Obese adolescents with T2DM } \\
\text { [8] }\end{array}$ & Breakfast & $98 \pm 25$ & $(12-16)$ & $\begin{array}{l}\mathrm{AUC}_{0-\text { inf }} \\
\quad 378.7 \pm 1.6\end{array}$ & $1.32^{\mathrm{e}}$ & - & - \\
\hline Healthy adults $[8]$ & Breakfast & $91 \pm 21$ & $(20-45)$ & $\begin{array}{l}\mathrm{AUC}_{0-\text { inf }} \\
\quad 398 \pm 1.7\end{array}$ & $1.26^{\mathrm{e}}$ & - & - \\
\hline $\begin{array}{l}\text { Healthy adults and adults with } \\
\text { T2DM [29] }\end{array}$ & - & $\begin{array}{l}71 \pm 14 \\
89 \pm 16\end{array}$ & $\begin{array}{l}27 \pm 6 \\
56 \pm 5\end{array}$ & - & $\begin{array}{l}1.27 \pm 0.27 \\
1.32 \pm 0.11\end{array}$ & $\begin{array}{l}559 \pm 163 \\
648 \pm 13.8\end{array}$ & - \\
\hline Obese adults [28] & Fasted & $114.6 \pm 26.1$ & $43.5 \pm 11.7$ & $\begin{array}{l}\mathrm{AUC}_{0-\text { inf }} \\
\quad 342 \pm 108\end{array}$ & $1.46^{\mathrm{e}}$ & $114.6 \pm 45.8^{\mathrm{f}}$ & - \\
\hline
\end{tabular}

Values are expressed as mean \pm standard deviation (range) unless specified otherwise

$A U C_{0-12}$ AUC concentrations from 0 to $12 \mathrm{~h}$ after dose, $A U C_{0-8}$ area under the curve concentrations from 0 to $8 \mathrm{~h}$ after dose, $A U C_{0-i n f}$ AUC until infinity, $C L / F$ oral clearance, $K a$ absorption rate constant, $T 2 D M$ type 2 diabetes mellitus, $T B W$ total body weight, $V / F$ oral volume of distribution ${ }^{a}$ Dose standardized (500 mg) AUC

${ }^{\mathrm{b}}$ Population mean

${ }^{c}$ Reported clearance of $0.33 \pm 0.033$ with fixed bioavailability of $60 \%$

${ }^{\mathrm{d}}$ Reported volume of $111 \pm 7$ with fixed bioavailability of $60 \%$

${ }^{\mathrm{e}}$ Calculated by $\mathrm{CL} / F=$ dose/AUC

${ }^{\mathrm{f}}$ Reported weight normalized $V / F$ of $1.0 \pm 0.41 / \mathrm{kg}$

(Fig. 1). The CL/F value in obese adolescents seems comparable to the value in non-obese adults [29] and similar to or lower than that in obese adults [28] (Table 3).

Explanations for the higher $\mathrm{CL} / F$ in overweight and obese adolescents versus non-obese children may differ. First, a higher tubular secretion of metformin by induced OCT2 and MATE1/MATE2K transporters in the kidney $[9,10]$ can be postulated in obese patients. This hypothesis is supported by our excess weight model, which shows an increase in $\mathrm{CL} / F$ with $\mathrm{WT}_{\text {excess }}$ (Fig. 3b) within the population of obese adolescents. Moreover, studies with intravenous procainamide, ciprofloxacin, and cisplatin, which are all primarily eliminated via tubular secretion, also show a higher clearance in obese adults than in nonobese adults [30]. These drugs are also renally transported by the OCT system: procainamide by OCT1-3 [31], ciprofloxacin by OCT and OAT (organic anion transporter) [31], and cisplatin by OCT2 [32]. In contrast, obese rodent models provide no basis for this hypothesis. High-fat-dietinduced mice do show a trend in increased OCT2 renal messenger RNA (mRNA) expression but no difference in OCT1 expression [33]. Ob/Ob and $\mathrm{db} / \mathrm{db}$ mice also show no difference in renal mRNA expression of the OCT1 transporter and even a decrease of the renal OCT2 and
MATE1 transporter [34-36]. However, these ob/ob and db/ $\mathrm{db}$ mice models may not be representative for obese patients, since these mice do not produce leptin or have no functional leptin receptor, and leptin may act on renal cells to regulate gene expression [33]. It is difficult to determine the net result of the various effects of obesity on the regulation of transporter expression in these rodent models [37], as pro-inflammatory cytokines, insulin, leptin, and cholesterol all have opposing effects on mRNA expression of the transporters [37]. In addition, renal transporters (OCT1-2 and MATE1/MATE2K) should be considered as a whole because they work together in the excretion of metformin, and one transporter can compensate the other [34]. Hence, our suggested increase in active tubular secretion by increased activity of the renal transporters in obese adolescents warrants further study. Another explanation for the higher $\mathrm{CL} / F$ in obese adolescents could be a decreased bioavailability $(F)$ in obese adolescents as a result of a decreased expression or activity of the intestinal transporters of metformin (i.e., OCT1, PMAT, OCT3). However, no literature is available about changes in intestinal transporter expression or activity with obesity, so this hypothesis remains rather speculative. Lastly, the higher $\mathrm{CL} / F$ in obese adolescents versus non-obese 
children may also to some extent be explained by difference in age (11-17.5 vs. 9 years, respectively). However, as this difference in age is small, this study suggests, in our opinion, that the increase in $\mathrm{CL} / F$ of metformin in obese adolescents may be explained by an increase in clearance or a decrease in oral bioavailability resulting from an increase or decrease in the activity in renal or intestinal transporters, respectively. Since the value for $\mathrm{CL} / F$ we report in obese adolescents is higher than in non-obese children [7] and comparable to the value in healthy adults and adults with T2DM [29], the maximum recommended dose of metformin $2 \mathrm{~g}$ for children may be considered to be increased to the maximum dose in adults (i.e., $3 \mathrm{~g}$ per day) where clinical response is lacking.

In this study, we could not identify an influence of genetic polymorphisms in the OCTI and MATEl transporter on the pharmacokinetics of metformin. It is likely that a larger number of patients is needed to accurately test this influence. Stocker et al. [38] was unable to identify an influence of the MATE1 promoter variant on the pharmacokinetics of metformin, whereas two other studies did find an influence of genetic variation in the $O C T 1$ transporter on the pharmacokinetic parameters of metformin [39, 40]. Stocker et al. [38] concluded that MATE1 and MATE2 transporters work together in the renal elimination of metformin and that genetic variants in MATE and OCT transporters should be considered together when determining the genetic determinants of renal elimination of metformin. For future studies, it would be interesting to evaluate the genetic variants of OCT1-3 and MATE1-2 together. In addition, it is of special interest to evaluate the genetic variants of the intestinal transporters of metformin (i.e., OCT1, OCT3 and PMAT) on the bioavailability [39] and oral absorption of metformin, since the oral absorption of metformin showed large interindividual variability in our data.

There are some limitations to this study. First, no nonobese adolescents were included because this pharmacokinetic study was part of a randomized double-blind controlled trial on metformin in obese adolescents with insulin resistance [11], precluding a head-to-head comparison with the obese adolescents. Second, our patients received metformin in a fasted state because, for ethical reasons, the pharmacokinetics study was performed during an OGTT for which a venous line was inserted for clinical purposes. In clinical practice, patients take metformin with food and as such our Ka may differ from that in other studies. Oral absorption varied widely between the obese adolescents. Nine adolescents had a very fast absorption, with a $T_{\max }$ of $60 \mathrm{~min}$, whereas the mean $T_{\max }$ in non-obese children was reported to be $2.4 \mathrm{~h}$ [7]. This difference may be explained by the fasted state of the obese adolescents or by the state of obesity.

\section{Conclusion}

We have shown that the $\mathrm{CL} / F$ of metformin increases significantly with TBW in overweight and obese adolescents. The increase in $\mathrm{CL} / F$ is explained by both $\mathrm{WT}_{\text {for age and length }}$ and $\mathrm{WT}_{\text {excess }}$, for which an excess weight model was proposed, in which $\mathrm{WT}_{\text {for age and length }}$ scaled allometrically to the power of 0.75 and a separate function for $\mathrm{WT}_{\text {excess }}$ was estimated. Compared with the literature, our $\mathrm{CL} / F$ value in obese adolescents is higher than in non-obese children, comparable to that in nonobese adults, and similar to or lower than that in obese adults. These results indicate that adult dosages of metformin could be considered in obese adolescents if pediatric dosages have been therapeutically ineffective.

Acknowledgements The authors thank Remko Harms for measuring the serum samples, Pyry Välitalo for supporting the VPC analysis, and Willem van den Brink for his support calculating the AUCs with $\mathrm{R}$ software. We thank Marieke Elst for her help conducting the clinical trial.

\section{Compliance with Ethical Standards}

Funding This study was funded by a Grant of the ZonMw (Grant no. 113201003) program of Priority Medicines for Children.

Conflict of interest A. van Rongen, M. P. van der Aa, M. Matic, R. H. N. van Schaik, V. H. M. Deneer, M. M. van der Vorst, and C. A. J. Knibbe have no conflicts of interest.

Ethics All procedures performed in studies involving human participants were in accordance with the ethical standards of the institutional and/or national research committee and with the 1964 Helsinki declaration and its later amendments or comparable ethical standards. Informed consent was obtained from all individual participants included in the study.

Open Access This article is distributed under the terms of the Creative Commons Attribution-NonCommercial 4.0 International License (http://creativecommons.org/licenses/by-nc/4.0/), which permits any noncommercial use, distribution, and reproduction in any medium, provided you give appropriate credit to the original author(s) and the source, provide a link to the Creative Commons license, and indicate if changes were made.

\section{References}

1. Ogden CL, Carroll MD, Kit BK, Flegal KM. Prevalence of childhood and adult obesity in the United States, 2011-2012. JAMA. 2014;311(2):806-14.

2. Ng M, Fleming T, Robinson M, Thomson B, Graetz N, Margono $\mathrm{C}$, et al. Global, regional, and national prevalence of overweight and obesity in children and adults during 1980-2013: a systematic analysis for the Global Burden of Disease Study 2013. Lancet. 2014;384(9945):766-81.

3. Cali AM, Caprio S. Obesity in children and adolescents. J Clin Endocrinol Metab. 2008;93(4):S31-6. 
4. Levy-Marchal C, Arslanian S, Cutfield W, Sinaiko A, Druet C, Marcovecchio ML, et al. Insulin resistance in children: consensus, perspective, and future directions. J Clin Endocrinol Metab. 2010;95(12):5189-98.

5. Fazeli Farsani S, Souverein PC, Overbeek JA, van der Vorst MM, Knibbe CA, Herings RM, et al. Long term trends in oral antidiabetic drug use among children and adolescents in the Netherlands. Br J Clin Pharmacol. 2015;80(2):294-303.

6. Neubert A, Hsia Y, de Jong-van den Berg LT, Janhsen K, Glaeske G, Furu K, et al. Comparison of anti-diabetic drug prescribing in children and adolescents in seven European countries. Br J Clin Pharmacol. 2011;72(6):969-77.

7. Sanchez-Infantes D, Diaz M, Lopez-Bermejo A, Marcos MV, de Zegher F, Ibanez L. Pharmacokinetics of metformin in girls aged 9 years. Clin Pharmacokinet. 2011;50(11):735-8.

8. Gao X, Christensen M, Burghen GA, Velasquez-Mieyer P, Moore KT, Donahue SR, et al. Pharmacokinetics of metformin in pediatric type 2 diabetic and healthy adult subjects. Clin Pharmacol Ther. 2003;65:46 (abstract PII).

9. Gong L, Goswami S, Giacomini KM, Altman RB, Klein TE. Metformin pathways: pharmacokinetics and pharmacodynamics. Pharmacogenet Genom. 2012;22(11):820-7.

10. Gorboulev V, Ulzheimer JC, Akhoundova A, Ulzheimer-Teuber I, Karbach U, Quester S, et al. Cloning and characterization of two human polyspecific organic cation transporters. DNA Cell Biol. 1997;16(7):871-81.

11. van der Aa MP, Elst MA, van Mil EG, Knibbe CA, van der Vorst MM. METFORMIN: an efficacy, safety and pharmacokinetic study on the short-term and long-term use in obese children and adolescents - study protocol of a randomized controlled study. Trials. 2014;15:207.

12. R Development Core Team. R: a language and environment for statistical computing. Vienna: R Foundation for Statatistical Computing, vol 42; 2008.

13. S. Beal, L. B. Sheiner, A. Boeckmann, R. J. Bauer. NONMEM User's Guides. (1989-2009). Ellicot City, MD, USA: Icon Development Solutions; 2009.

14. Keizer RJ, Karlsson MO, Hooker A. Modeling and Simulation Workbench for NONMEM: Tutorial on Pirana, PsN, and Xpose. CPT Pharmacometrics Syst Pharmacol. 2013;2(43):e50.

15. Beal SL. Ways to fit a PK model with some data below the quantification limit. J Pharmacokinet Pharmacodyn. 2001;28(39):481-504.

16. Byon W, Fletcher CV, Brundage RC. Impact of censoring data below an arbitrary quantification limit on structural model misspecification. J Pharmacokinet Pharmacodyn. 2008;35(40):101-16.

17. Savic RM, Jonker DM, Kerbusch T, Karlsson MO. Implementation of a transit compartment model for describing drug absorption in pharmacokinetic studies. J Pharmacokinet Pharmacodyn. 2007;34(41):711-26.

18. Bergstrand M, Hooker AC, Wallin JE, Karlsson MO. Predictioncorrected visual predictive checks for diagnosing nonlinear mixed-effects models. AAPS J. 2011;13(27):143-51.

19. Janmahasatian S, Duffull SB, Ash S, Ward LC, Byrne NM, Green B. Quantification of lean bodyweight. Clin Pharmacokinet. 2005;44(19):1051-65.

20. Foster BJ, Platt RW, Zemel BS. Development and validation of a predictive equation for lean body mass in children and adolescents. Ann Hum Biol. 2012;39(21):171-82.

21. Peters AM, Snelling HL, Glass DM, Bird NJ. Estimation of lean body mass in children. Br J Anaesth. 2011;106(20):719-23.

22. Fadem SZ, Rosenthal B. Bedside Schwartz and Counahan-Barratt Methods. 2012. http://nephron.com/bedside_peds_nic.cgi. Accessed 31 Aug 2015.
23. Becker ML, Visser LE, van Schaik RH, Hofman A, Uitterlinden $\mathrm{AG}$, Stricker BH. Interaction between polymorphisms in the OCT1 and MATE1 transporter and metformin response. Pharmacogenet Genom. 2010;20(1):38-44.

24. van Rongen A, Vaughns JD, Moorthy GS, Barrett JS, Knibbe CA, van den Anker JN. Population pharmacokinetics of midazolam and its metabolites in overweight and obese adolescents. Br J Clin Pharmacol. 2015;80(5):1185-96.

25. TNO. De TNO groeicalculator voor professionals. https:// groeiweb.pgdata.nl/calculator.asp. Accessed 14 Nov 2015.

26. Food and Drug Administration Center for Drug Evaluation and Research. Advisory Committee for Pharmaceutical Science and Clinical Pharmacology (ACPS-CP) meeting, Summary minutes and FDA transcript. March 14, 2012.

27. Knibbe CA, Brill MJ, van Rongen A, Diepstraten J, van der Graaf PH, Danhof M. Drug disposition in obesity: toward evidencebased dosing. Annu Rev Pharmacol Toxicol. 2015;55(1):149-67.

28. Padwal RS, Gabr RQ, Sharma AM, Langkaas LA, Birch DW, Karmali S, et al. Effect of gastric bypass surgery on the absorption and bioavailability of metformin. Diabetes Care. 2011;34(6):1295-300.

29. Graham GG, Punt J, Arora M, Day RO, Doogue MP, Duong JK, et al. Clinical pharmacokinetics of metformin. Clin Pharmacokinet. 2011;50(2):81-98.

30. Brill MJ, Diepstraten J, van Rongen A, van Kralingen S, van den Anker JN, Knibbe CA. Impact of obesity on drug metabolism and elimination in adults and children. Clin Pharmacokinet. 2012;51(71):277-304.

31. Bauer LA, Black DJ, Lill JS, Garrison J, Raisys VA, Hooton TM. Levofloxacin and ciprofloxacin decrease procainamide and $\mathrm{N}$ acetylprocainamide renal clearances. Antimicrob Agents Chemother. 2005;49(4):1649-51.

32. Ciarimboli G, Lancaster CS, Schlatter E, Franke RM, Sprowl JA, Pavenstadt $\mathrm{H}$, et al. Proximal tubular secretion of creatinine by organic cation transporter OCT2 in cancer patients. Clin Cancer Res. 2012;18(4):1101-8.

33. More VR, Slitt AL. Alteration of hepatic but not renal transporter expression in diet-induced obese mice. Drug Metab Dispos. 2011;39(6):992-9.

34. Clarke JD, Dzierlenga AL, Nelson NR, Li H, Werts S, Goedken MJ, et al. Mechanism of altered metformin distribution in nonalcoholic steatohepatitis. Diabetes. 2015;64(9):3305-13.

35. Canet MJ, Hardwick RN, Lake AD, Dzierlenga AL, Clarke JD, Goedken MJ, et al. Renal xenobiotic transporter expression is altered in multiple experimental models of nonalcoholic steatohepatitis. Drug Metab Dispos. 2015;43(2):266-72.

36. More VR, Wen X, Thomas PE, Aleksunes LM, Slitt AL. Severe diabetes and leptin resistance cause differential hepatic and renal transporter expression in mice. Comp Hepatol. 2012;11(1):992-9.

37. Jang EH, Kim HK, Park CS, Kang JH. Increased expression of hepatic organic cation transporter 1 and hepatic distribution of metformin in high-fat diet-induced obese mice. Drug Metab Pharmacokinet. 2010;25(4):392-7.

38. Stocker SL, Morrissey KM, Yee SW, Castro RA, Xu L, Dahlin A, et al. The effect of novel promoter variants in MATE1 and MATE2 on the pharmacokinetics and pharmacodynamics of metformin. Clin Pharmacol Ther. 2013;93(2):186-94.

39. Shu Y, Brown C, Castro RA, Shi RJ, Lin ET, Owen RP, et al. Effect of genetic variation in the organic cation transporter 1, OCT1, on metformin pharmacokinetics. Clin Pharmacol Ther. 2008;83(2):273-80.

40. Tzvetkov MV, Vormfelde SV, Balen D, Meineke I, Schmidt T, Sehrt $\mathrm{D}$, et al. The effects of genetic polymorphisms in the organic cation transporters OCT1, OCT2, and OCT3 on the renal clearance of metformin. Clin Pharmacol Ther. 2009;86(3):299-306. 